\title{
Solenoid Device
}

National Cancer Institute

\section{Source}

National Cancer Institute. Solenoid Device. NCI Thesaurus. Code C50181.

An electronic device consisting of a coil surrounding a movable iron core that is designed to act as a switch or relay. 